\title{
Effect of Double Pulse MIG Welding on Porosity Formation on Aluminium 5083 Fillet Joint
}

\author{
Eakkachai Warinsiriruk ${ }^{1}{ }^{*}$, Jukkapun Greebmalai ${ }^{1}$, and Montri Sangsuriyun ${ }^{2}$ \\ ${ }^{1}$ Department of Industrial Engineering, Faculty of Engineering, Mahidol University \\ ${ }^{2}$ Department of Industrial Engineering, Faculty of Engineering, Nakhon Phanom University
}

\begin{abstract}
In this article, parameters of Double-Pulse Metal Inert Gas Welding (DP-MIG) was used for minimising a porosity formation in a T-joint fillet weld. AA5083-H112 aluminium alloy (Non-heat treatable series) with the plate thickness of 10 millimetres is base metal for this study. Welding consumables were filler wire ER5356 with a diameter of 1.2 millimetres and shielded by industrial argon gas. Three majorities parameter of DP-MIG were Delta wire feed (m/min), Frequency $(\mathrm{Hz})$ and Duty cycle $(\%)$. Measurable signal current pattern and opened porosity on the fractured surface were couple observed to study their relationships. An appropriate image processing technique was employed to quantitative measuring and calculating a size grouping area of several opened porosities overall weld length, precisely. The result found that the optimal was used a low-level of Delta wire feed of $0.8 \mathrm{~m} / \mathrm{min}$, a high-level of a frequency of $5.0 \mathrm{~Hz}$, a mid-level of the duty cycle $30 \%$ and a high travel speed $60 \mathrm{~cm} / \mathrm{min}$ could minimise the porosity formation with complete penetration.
\end{abstract}

\section{Introduction}

Aluminum alloy has been used widely of a light-weight structure such as an electric vehicle (EV), transport chemical tank, aerospace etc. Metal Active Gas (MIG) is commonly used for automatic joining process in smart factory. Welding engineer has attempted joining aluminum alloy which desire a complete joint fusion, free porosity and so on. Especially, when welding a thick plate as over 10 millimeters that risk of lack of fusion occurrence. Applying a high welding current condition may encounter a problem of lack of fusion but several numbers of porosity forms in weldment and also a problem of HAZ' grain growth. Multiple-passes procedures with low welding current and low deposition rate welding by GTAW does not respond a high productivity. Single-pulsed MIG (P-GMAW) process had developed for improving the process capability as mentioned before. However, it is a limitation for a thick plate of aluminum welding by one droplet per pulse. Because of P-GMAW usually performs at low frequency for pulse generation. Then, an unstable arc through a filler breakdown and a lack of fusion still occurs, frequently.

Recently, the double-pulse metal inert gas welding (DP-MIG) technology has been developed for improving capability of an aluminium welding process. Note that double pulse will have been used as DP abbreviation. Important parameters of DP-MIG are high frequency, delta wire feeding speed and duty cycle. The high frequency is adjusted to ensure one droplet transfer per pulse [1-2]. While a delta wire feeding speed is changing the size of droplets [1-4]. In pulse stage can be adjusted by changing a duty cycle period to obtaining the shape of metal droplets in pulse and transfer mode for weld bead shape $[1,3,4]$. DP-MIG is reported successful welding on thin plate of aluminum alloy. Parameters effect on weld quality is investigated in those conditions. However, the aluminium welding on a thick plate, high deposition rate has not been investigated in DP-MIG parameters affect porosity formation, qualitatively.

This article, studying the effect of DP-MIG parameters on a T-joint fillet weld for aluminium alloy 5083 with the thickness of $10 \mathrm{~mm}$. To determine the optimised parameter level which can obtain a minimise porosity formation with complete joint fusion. The fatigue life was also evaluated to identify that an optimised parameter had a suitable property.

\section{Experimental Procedure and Measuring Procedure}

\subsection{Material Preparations, Equipment and Parameters}

Aluminium alloy 5083 with a thickness of $10 \mathrm{~mm}$ was used as the base metal. In this study, the aluminium filler metal ER 5356 with a diameter of $1.2 \mathrm{~mm}$ and shielding by industrial argon gas was used to create a welded joint $\mathrm{T}$-joint fillet welded is the configuration for the study which is universal joint has been serviced in a general cycling structure. For the welding process, the basic 
experiment set-up consists of Double-Pulse MIG power supply of Fronius TPS 500i, and an accuracy data precision system for welding current signal. Fig 1 shows the schematic of the experimental set-up. Welding robotic Fanuc arc mate 100ib was employed for controlling a precision welding motion, respectively.

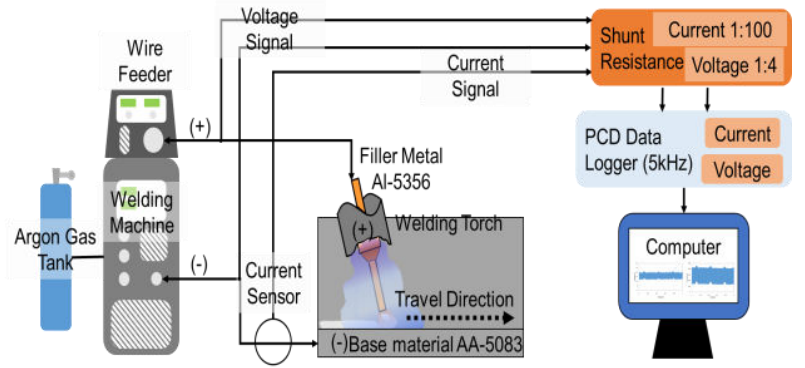

Fig 1. Experimental Schematic

To clearly understand, the cause and effect of DP parameters, DP-current signal during joining were detected to get an actual level of a DP pattern. Calibrated current sensing with hall sensor was connected through DAC device by the sampling rate of 5000 sample per second for converting and storing in the computer. The measured DP current signal clearly shown in Fig 2 that process the data acquired is a suitable monitoring system. Measuring of delta wire feed or DP current range, DP duty cycle and DP frequency were defined in Fig 2 for studies variable, DP current range is 5 to 80 amperes, DP frequency 0.5 to $3 \mathrm{~Hz}$ and DP duty cycle 10 to $90 \%$. Set of the studied variables shown in table 1 . During the experiment, the welded result was evaluated as step by step to understand a trend of the porosity formation from each level of the experiment. It must be noticed that a suitable level of DP current range was set in the experiment of the frequency experiment. Moreover, the suitable level DP current and frequency were set in the duty-cycle experiment.

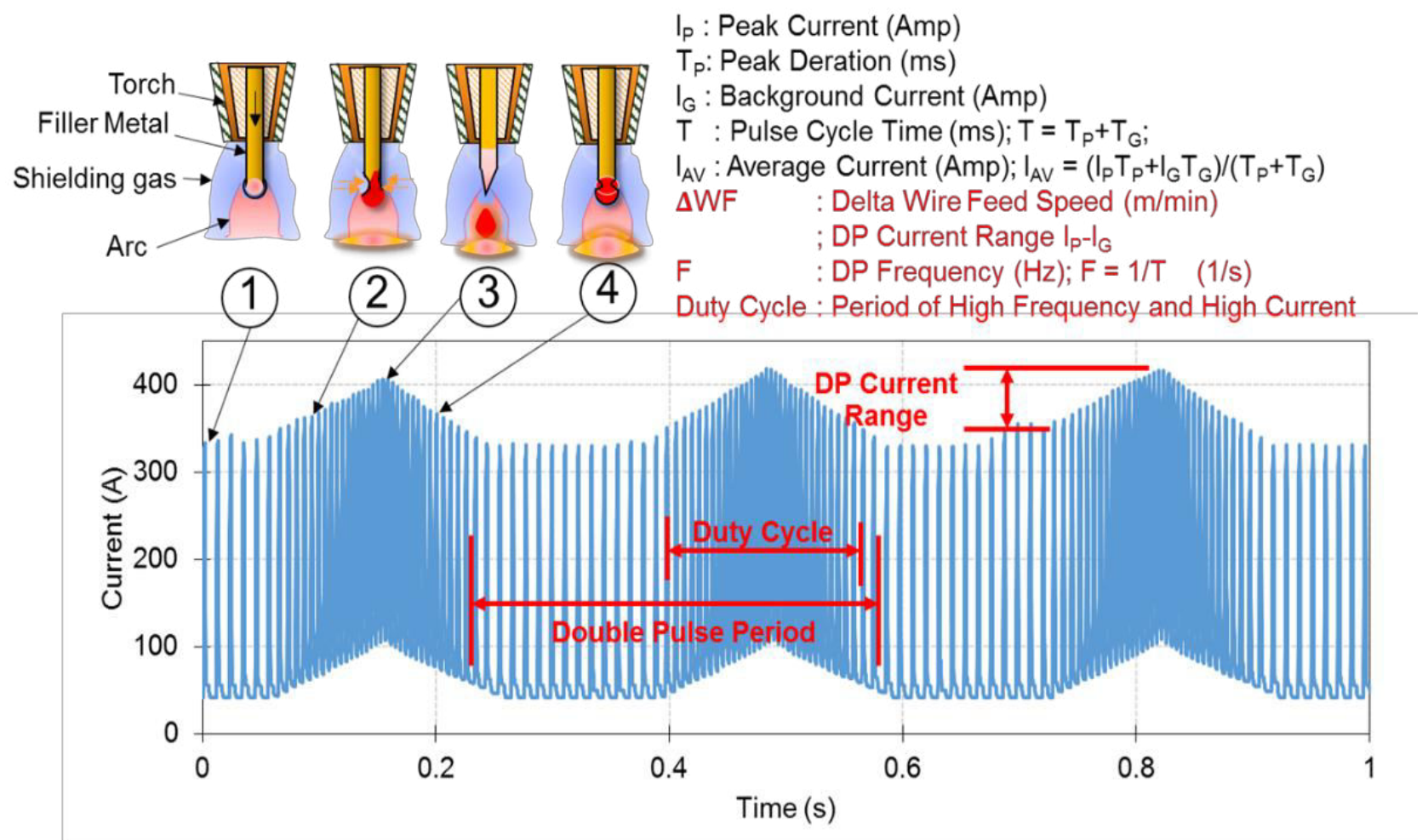

Fig 2. An illustration of measured double pulse (DP) signal related metals transfer and defined parameter 
Table 1. Process parameters and studied variables

\begin{tabular}{|c|c|c|c|c|c|}
\hline $\begin{array}{c}\text { Experiment } \\
\text { Number }\end{array}$ & $\begin{array}{l}\text { Wire Feed Speed } \\
\qquad \mathrm{m} / \mathrm{min}\end{array}$ & $\begin{array}{c}\text { Delta Wire Feed Speed } \\
\text { m/min }\end{array}$ & $\begin{array}{l}\text { DP Current } \\
\text { Range } \\
\text { Ampere }\end{array}$ & $\begin{array}{c}\text { Frequency } \\
\mathrm{Hz}\end{array}$ & $\begin{array}{c}\text { Duty Cycle } \\
\%\end{array}$ \\
\hline 1 & 11 & $\underline{0.1}$ & $\underline{\mathbf{5}}$ & 3 & 30 \\
\hline 2 & 11 & $\underline{0.8}$ & $\underline{20}$ & 3 & 30 \\
\hline 3 & 11 & $\underline{\mathbf{3}}$ & $\underline{55}$ & 3 & 30 \\
\hline 4 & 11 & $\underline{4.8}$ & $\underline{70}$ & 3 & 30 \\
\hline 5 & 11 & $\underline{6}$ & $\underline{80}$ & 3 & 30 \\
\hline 6 & 14.9 & 0.4 & 20 & $\underline{0.5}$ & 50 \\
\hline 7 & 14.9 & 0.4 & 20 & $\overline{\underline{3}}$ & 50 \\
\hline 8 & 15 & 0.4 & 20 & 3 & $\underline{10}$ \\
\hline 9 & 15 & 0.4 & 20 & 3 & $\overline{30}$ \\
\hline 10 & 15 & 0.4 & 20 & 3 & $\overline{\mathbf{5 0}}$ \\
\hline 11 & 15 & 0.4 & 20 & 3 & $\underline{90}$ \\
\hline
\end{tabular}

\subsection{Measurement of Porosity on Welded Joint}

The internal porosity on overall weld length could be open and visual measured by using the fillet break testing. Lack of fusion was also able measured in the same method. Fig 3 shown the fracture appearance and opened porosity can be seen clearly.

For good repeatability of measurement for several numbers of opened porosity, image processing was applied in this study by 8-bit transferred image, $10 \%$ $\mathrm{B} \& \mathrm{~W}$ threshold adjusting and detect porosity with analyse partial applied $0.30-1$ circularity, and also ignore porosity size less than $0.10 \mathrm{~mm}^{2}$. The Image-J program was employed for this measuring and the process of image processing was shown as an illustration in Fig 4.

The three porosity groups diameter were classified to get more measuring resolution. The three groups had been defined as:

Group 1: diameter smaller than $1.5 \mathrm{~mm}$
Group 2: diameter between 1.5 to $3 \mathrm{~mm}$

Group 3: diameter larger than $3 \mathrm{~mm}$

Fig 5 shown a detectable result from a procedure as above mention that given a satisfying result. Verifying an accuracy complete with manually counting had an error lesser than $5 \%$. Therefore, the typical procedure for image processing was used for this investigation.

\subsection{Fatigue Strength Testing}

The mechanical properties are represented by fatigue strength. The fatigue testing used 10 hertz for complete reversal stress apply. An optimized parameters from the finding was selected to join as the double fillet welds in the $\mathrm{T}$-joint for performing the fatigue test.

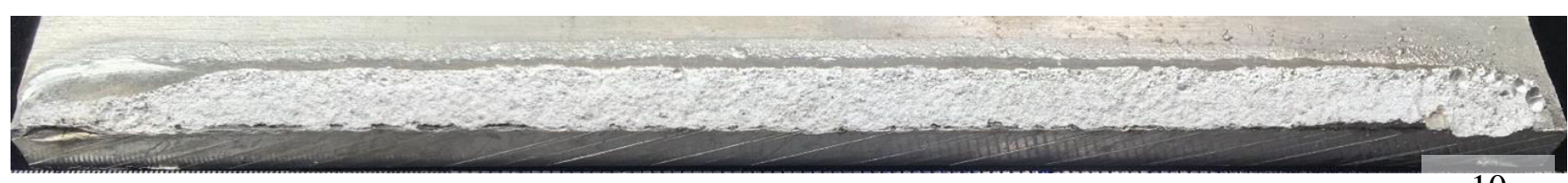

Fig 3. Fracture Surface

\section{(a) Original}

(b) Threshold:

(c) Tmage- $P$

(d) Manual

Fig 4. Fractured surface shows the evidence of porosity from fillet break test and transformation of image by the typical image processing. 


\section{Experimented Discussion}

Results of the experiment were shown in Fig 5, 6 and 7. Fig 5 shows the results of DP current signal which measured during welding. In this paper shown only the minimum and the maximum for each variable. Also, the results of a couple of weld-bead appearances and the fractured surface which have opened porosity for each variable shown in Fig 6. Moreover, Fig 7 shows the quantitative data of summation of the opened-porosity area $\left(\mathrm{mm}^{2}\right)$ for three groups under the influence of studied DP-MIG parameters.

\subsection{DP Current Range Effect}

Five runs of the DP-current range were 5, 20, 55, 70 and 80 ampere from the adjusted the delta wire feed speed of $0.1,0.8,3,4.8$ and $6 \mathrm{~m} / \mathrm{min}$, respectively. The results of summation porosity area for three groups under the influence of studied variables were plotted and shown in
Fig 7(A). It was founded that increasing of DP current range increases the sum porosity area. Porosity group 3 (having a diameter larger $3 \mathrm{~mm}$ ) have a number increased while the group of 1 and 2 have a number also increased. It implies that by increasing DP current range from 5 amperes to 80 amperes resulted in increasing the large porosity formation from high energy in the weld pool. Also, diffusion of the small size of porosity became a large size porosity in high energy stage.

However, lack of fusion at weld root was found by visual inspection from the experiment number 1 which DP-current range was set and welded at 5 amperes delta wire-feed speed $0.1 \mathrm{~m} / \mathrm{min}$ ). For other DP-current ranges were not detect of lack of fusion. This is evidence that DP-current range affects melting ability.

Increasing DP-current range or increasing the delta wire feed speed increases weld penetration (degree of metal smelting). However, it is an interaction for a negative quality of porosity formation. Then, a few increasing DP-current as 20 amperes (delta wire-feed speed $0.8 \mathrm{~m} / \mathrm{min}$ ) could provide a minimise porosity formation with a complete fusion on a welded joint
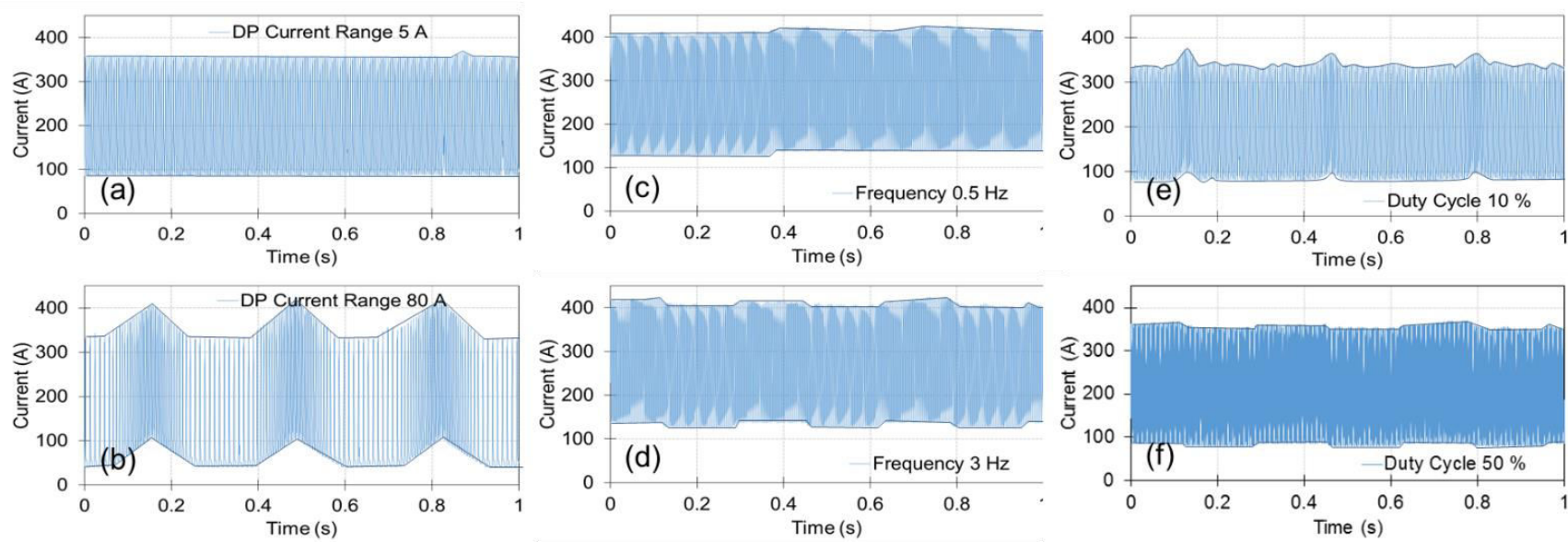

Fig 5. Meaasured DP Current Signal

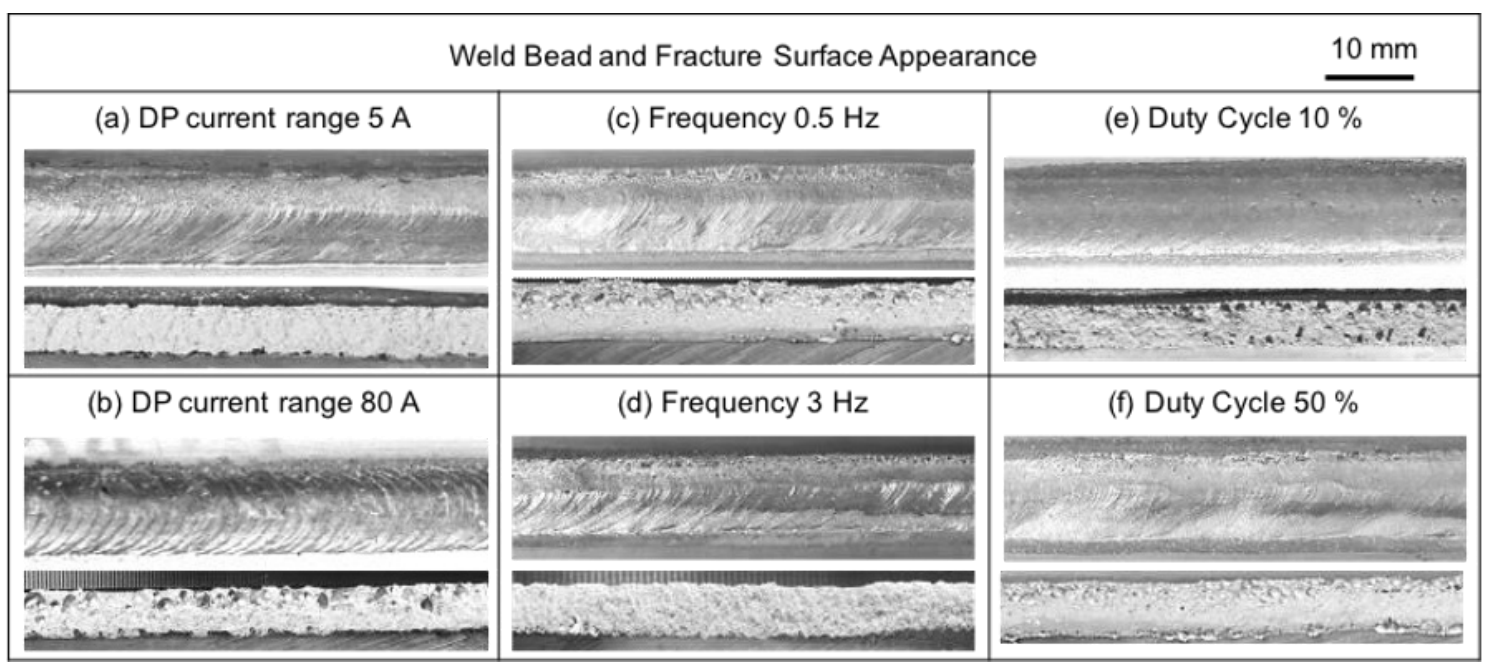

Fig 6. Welding Bead and Fracture Surface Result 


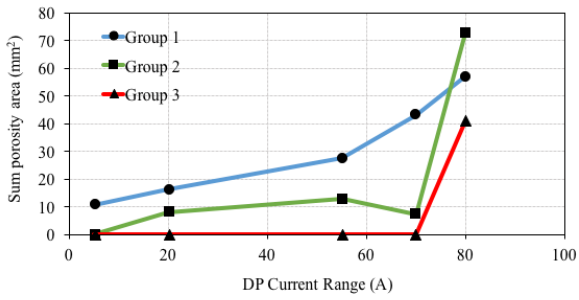

7(A) Effect of DP-Current Range

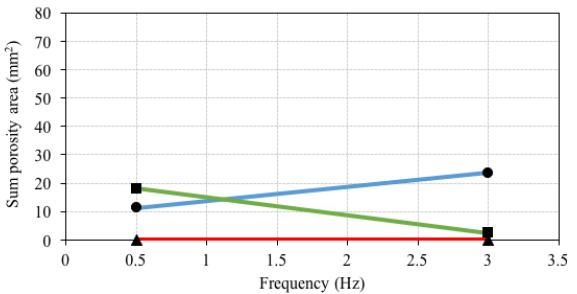

7(B) Effect of Frequency

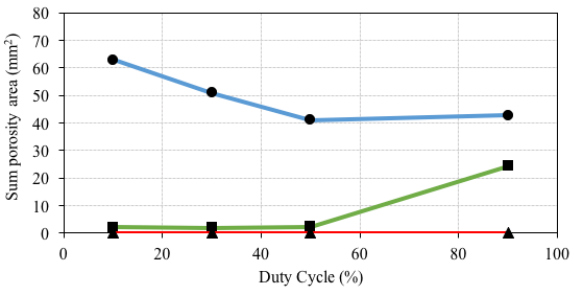

7(C) Effect of Duty Cycle

Fig 7. Effect of DP-MIG parameters on a summation of opened porosity area.

\subsection{DP Frequency Effect}

Fig 7 (B) shows the results of porosity area under the influence of the DP frequency. A suitable DP-current range of 20 amperes which provided a minimise porosity area from the previous section was used as the parameter in these two runs experiment. DP-frequency of $0.5 \mathrm{~Hz}$ and $3 \mathrm{~Hz}$ were varied. It was found that the group 3 of the large-size porosity disappeared on both levels. Group 1 and 2 have occurred in low level compared with the effect of DP-current range but does not a significant difference.

Refer to a DP signal of $0.5 \mathrm{~Hz}$ frequency in Fig 5; peak current pulse was raised in a long period. Due to the low heat input concept, an extended pulse period is not corresponding for aluminium welding. Then, a shorter pulse period by $3 \mathrm{~Hz}$ frequency was preferentially selected as a suitable parameter

\subsection{Duty Cycle Effect}

The adjusting of the duty cycle affected on a width of the high current pulse. Measured DP signals of low level and high level of duty cycle were shown in Fig 5, assist in understanding the DP shape.

The DP-current range of 20 amperes and a frequency of $3 \mathrm{~Hz}$ were fixed for four experiment of duty cycle effect. Results of summation of porosity area were plotted and shown in Fig 7 (C). Low level of a duty cycle of DP that significantly affected the high amount of the formation of a group 1 porosity (small size porosity). Increasing a duty cycle decreases the amount of group 1 formation, but this behaviour, it was found that a group 1 porosity could not be fixed as a perfect zero. Meanwhile, the formation of group 2 porosity for a low level of duty cycle could be controlled in minimum formation. High level of duty cycle with $90 \%$ affected the increasing of a group 2 porosity. Moreover, the group 3 porosity disappeared in all duty-cycle level when the suitable level of the DP current range and the frequency were set.

According to the experiment number 2, the combination of parameters with DP-current range of 20 amperes, delta wire feed speed of $0.8 \mathrm{~m} / \mathrm{min}$, the frequency of $3 \mathrm{~Hz}$ and duty cycle of $30 \%$ was optimised.

\subsection{Fatigue Strength}

Optimized parameters of DP-MIG which is the DPcurrent range of 20 amperes (Delta wire feed speed 0.8 $\mathrm{m} / \mathrm{min}$ ), the duty cycle of $30 \%$ and frequency of $5 \mathrm{~Hz}$ was tested in fatigue testing. Double fillet weld was a specimen for a test in complete cyclic loading. In this section, Double fillet weld which joined by DC-MIG was also tested to compare a joint-strength service aspect. Equivalent leg size of $8 \mathrm{~mm}$ was obtained from DC MIG condition of current 262 amperes and 26.2 voltage. Fig 8, the fatigue tested result shows that DP MIG joint has better strength in cycle service condition than DC joint weld in the same condition of applied stress. Approximate 2 times of cyclic life of DP MIG joint over DC MIG joint. Considering a joint performance by IIW S-N curve with joint category No. 23, DP MIG joint which was joined by optimised parameters, acceptable a joint performance.

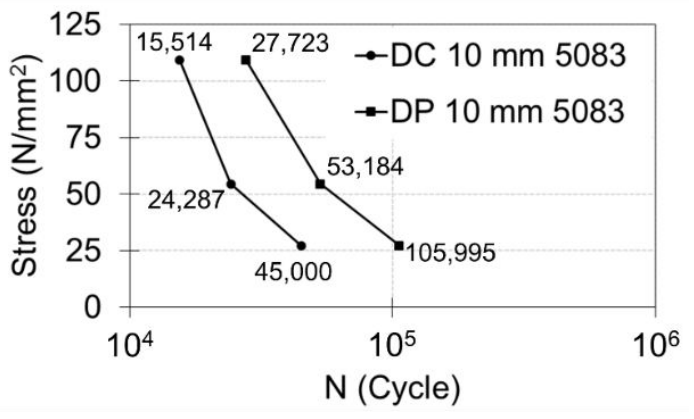

Fig 8. S-N Curve DC and DP-MIG Comparing

\section{Conclusion}

Parameters DP-MIG were investigated the effect on porosity formation for the fillet welding with aluminumalloy of AA5083 H-112. It can be concluded that:

1.The delta wire feeding speed or the DP current range most significantly affected the porosity formation. High DP current range provides a poor weld bead which contained the large size porosity. It must be noted that a low DP current range as near as zero has negative affected a complete fusion. 
2. The DP frequency does not significantly affected the formation of porosity but it was discussed for controlling heat input.

3. The duty cycle naturally affected the porosity formation for small size. Optimized parameter was DP-current range of 20 ampere, delta wire feed speed of $0.8 \mathrm{~m} / \mathrm{min}$, frequency of $3 \mathrm{~Hz}$ and duty cycle of $30 \%$.

The DP-MIG joint has better strength in a fatigue service condition than DC-MIG joint weld in the same condition of applied cyclic stress

\section{Reference}

1. Liu A, Tang X, Lu F. Study on welding process and prosperities of AA5754 Al-alloy welded by double pulsed gas metal arc welding. Materials \& Design. 2013 Sep 1;50:149-55.

2. Praveen P, Yarlagadda PK, Kang MJ. Advancements in pulse gas metal arc welding. Journal of Materials Processing Technology. 2005 May 15;164:1113-9.

3. Ueguri S, Hara K, Komura H. Study of metal transfer in pulsed GMA welding. Welding journal. 1985 Aug;64(8):242-50.

4. Adam G, Siewert TA. Sensing of GMAW droplet transfer modes using an ER100S-1 electrode. Welding Journal. 1990 Mar 1;69(3):103s-8s. 